\title{
Multi-Frequency GPR Data Fusion with Genetic Algorithms for Archaeological Prospection
}

\author{
Wenke Zhao ${ }^{1, *}$, Lin Yuan ${ }^{1}$, Emanuele Forte ${ }^{2} \mathbb{D}$, Guoze Lu ${ }^{1}$, Gang Tian ${ }^{1}$ and Michele Pipan ${ }^{2}$ \\ 1 School of Earth Sciences, Zhejiang University, Hangzhou 310058, China; 22038028@zju.edu.cn (L.Y.); \\ 21838025@zju.edu.cn (G.L.); tiangang@zju.edu.cn (G.T.) \\ 2 Department of Mathematics and Geosciences, University of Trieste, 34128 Trieste, Italy; eforte@units.it (E.F.); \\ pipan@units.it (M.P.) \\ * Correspondence: zhaowenke@zju.edu.cn
}

Citation: Zhao, W.; Yuan, L.; Forte,

E.; Lu, G.; Tian, G.; Pipan, M.

Multi-Frequency GPR Data Fusion

with Genetic Algorithms for

Archaeological Prospection. Remote

Sens. 2021, 13, 2804. https://doi.org/

$10.3390 /$ rs13142804

Academic Editors: Carl Philipp Lipo and Timothy S. de Smet

Received: 22 June 2021

Accepted: 15 July 2021

Published: 16 July 2021

Publisher's Note: MDPI stays neutral with regard to jurisdictional claims in published maps and institutional affiliations.

Copyright: (c) 2021 by the authors. Licensee MDPI, Basel, Switzerland. This article is an open access article distributed under the terms and conditions of the Creative Commons Attribution (CC BY) license (https:/ / creativecommons.org/licenses/by/ $4.0 /)$.

\begin{abstract}
Archaeological GPR data from antennas of different frequencies allow the identification of buried cultural heritage at different scales. Therefore, multi-frequency GPR systems are recommended for complicated subsurface archaeological conditions. GPR data fusion approaches, automatically or semi-automatically, can integrate data measurements from different frequency antennas, combine them into a single representation, and partially overcome the unavoidable tradeoff between penetration and resolution. We propose an adaptively weighted fusion method for multi-frequency GPR data based on genetic algorithms (GAs). In order to evaluate the feasibility and the effectiveness of the strategy for archaeological prospection, we tested the procedure on GPR datasets acquired in two totally different archaeological conditions: rammed layers of an ancient wall, in Henan Province, China, and complex and elusive prehistoric archaeological features within a natural stratigraphic sequence on the volcanic Stromboli Island, Italy. The results demonstrate that the proposed strategy can maximize the information content of GPR profiles, enhancing the GPR interpretation possibilities in an automatic and objective way for different targets and in different subsurface conditions.
\end{abstract}

Keywords: multi-frequency GPR data fusion; archaeological prospection; genetic algorithms

\section{Introduction}

Ground-penetrating radar (GPR) is a well-accepted near-surface geophysical technique to image and characterize subsurface targets, based on changes in the electromagnetic properties of materials. With relatively fast data acquisition, GPR has been used to solve more and more subsurface problems in the field of archaeology efficiently and accurately [1-3]. According to the propagation characteristics of the EM wave, higherfrequency GPR signals offer higher resolution while lower-frequency GPR signals offer greater depth of penetration. In order to avoid limitations in imaging, multi-frequency GPR systems are often used for complicated subsurface archaeological conditions [4-10]. Particularly, GPR mappings for reconstruction of ancient landscapes associated with archaeological sites in a sequence stratigraphic context require a deeper sedimentary record as well as enhanced high-resolution shallow imaging $[11,12]$. On the other hand, multichannel systems involving multi-frequency arrays have permitted an enormous increase in survey efficiency and spatial sampling resolution, and have greatly improved the areal coverage for large-scale archaeological fieldwork [13-16].

GPR data fusion approaches, automatically or semi-automatically integrating data measurements extracted from antennas of different frequencies and combining them into a single representation, are therefore proposed to overcome the unavoidable trade-off between penetration and resolution, and to produce accurate, robust, and reliable estimates of different subsurface structures [17-22]. Multi-frequency GPR data fusion has improved imaging and interpretability compared to standard data processing and interpretation [21], 
and has attracted many researchers from academia and industry because of its foreseen benefits, which include, but are not limited to, enhanced confidence and reliability of measurements, extended spatial and/or temporal coverage, and reduced uncertainties, such as those associated with surveys performed with a single frequency.

Within this context, most approaches focus on multi-frequency GPR data fusion using statistical methods and probabilistic techniques, accomplished in time or frequency domains [17]. In most studies, it is difficult to keep the smoothness of the transition in the section obtained by merging high- and low-frequency profiles, and it is also inappropriate when the overlap of the spectrum bandwidth is not good enough [19]. Moreover, there is not a fusion algorithm which is suitable for any multi-frequency GPR surveys, due to the complexity of application scenarios.

Therefore, we introduce genetic algorithms (GAs) to calculate the time-varying weight factors for datasets to be fused, in order to keep the largest number of dominant components from GPR profiles of different frequencies: the forward segment of the integrated representation outcomes has more high-frequency components, while the backward one has more components shifted to low frequencies. We also perform tests on multi-frequency GPR datasets acquired in two totally different archaeological conditions, such as for a topographic surface, buried structures, age of archaeological remains, geological background, and contrast between targets and surrounding materials, to evaluate the applicability and the effectiveness of the proposed strategy for archaeological prospection and the attainable improvements in the characterization of spatial distribution and internal structures.

\section{Methodology}

Genetic algorithms (GAs) simulate the evolution mechanism of natural organisms, learning from the elimination rule of natural selection to search for the optimal solution [23]. The process of GAs is summarized as follows:

(1) Initialization: the initial population consists of a random generation of $\mathrm{N}$ number of $\mathrm{X}$ individuals. Each individual (also called a chromosome) encodes the variables of the problem:

$$
X_{i}^{G}=\left\{X_{i, 1}^{G}, X_{i, 2}^{G}, \ldots, X_{i, L}^{G}\right\}, i=1,2, \ldots, N
$$

where $L$ denotes the number of the variables, and $G$ is the generation.

(2) Assessment: formulate the objective function to calculate the fitness values of the population in the current generation.

(3) Termination: end up at termination conditions.

(4) Genetic manipulation:

- Selection;

- Crossover operator;

- Mutation operator.

(5) Replacement: replace the worst individuals with the new children.

(6) Go back to step (2), and count $G=G+1$.

The function of the crossover is to recombine and inherit excellent genes, while an appropriate mutation rate can maintain the genetic diversity of the population. The flow chart of multi-frequency GPR data fusion for the proposed strategy is reported in Figure 1. In the application GAs to multi-frequency GPR datasets, the data from the various antennas should be transformed into the same space-time coordinates. Moreover, amplitude normalization and resampling of each single frequency dataset are necessary before data fusion. 


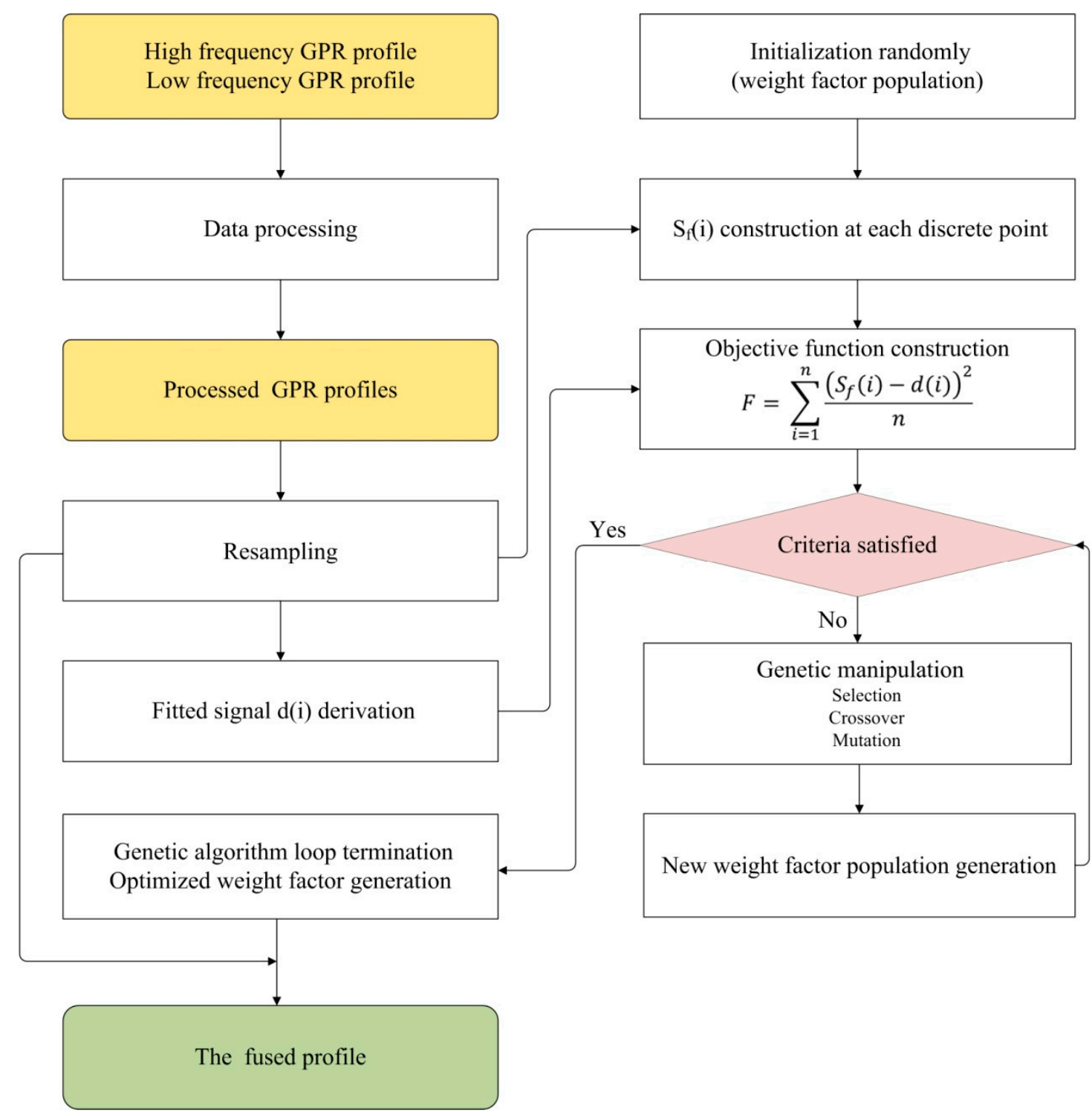

Figure 1. Flow chart of multi-frequency GPR data fusion strategy exploiting genetic algorithms.

If $S_{h}$ and $S_{l}$ are the high- and low-frequency signals, respectively, the weighted fused signal is

$$
S_{f}=W * S_{h}+(1-W) * S_{l}
$$

where $W$ is the weight factor to be solved by means of the GA.

We simulate the solving process of the optimal weight factor as species evolution. Firstly, a population size equal to 500 is adopted in the model, and the length of $n$, i.e., the number of the weight factors, is set as the number of samples of the signal. Then, 500 models can be randomly generated as:

$$
m=\left\{w_{1}, w_{2}, \ldots, w_{n}\right\}
$$

The population can be described as:

$$
p_{i}^{G}=\left\{m_{1}^{G}, m_{2}^{G}, \ldots, m_{500}^{G}\right\}
$$


In addition, we choose the least squares method to build the objective function:

$$
F=\sum_{i=1}^{n} \frac{\left(s_{f}(i)-d(i)\right)^{2}}{n}
$$

where $S_{f}(i)$ denotes the amplitudes of the discrete fused signal, and the discrete fitted signal $d(i)$ is synthesized by the high- and low-frequency signals as:

$$
d(i)=\left\{\begin{array}{l}
S_{h}(i), i \leq n_{0} \\
S_{l}(i), i>n_{0}
\end{array}\right.
$$

where $n_{0}$ means the sample where the accumulated energy over time reaches a threshold value with regard to the signal from the high-frequency GPR profile. Based on extensive tests, the optimum threshold is around $90 \%$ of the high-frequency energy. The objective function is used to minimize the difference between the fused signal and the fitted signal.

\section{Results}

3.1. Case Study I: Multi-Frequency GPR Data Fusion to Characterize Rammed Layers within an Ancient Wall

Case study I focuses on 2D multi-frequency GPR surveys of the rammed earth wall of the ancient Gong Site, located at Huixian, Henan Province, China, collected with combined $250 \mathrm{MHz}$ and $800 \mathrm{MHz}$ central-frequency antennas (Figure 2). Gong is an ancient vassal state of the Western Zhou Dynasty (1046-771 BC), when dozens of vassal states were distributed in the Central Plains of China. The rammed earth wall surrounding the ancient city was built about 3000 years ago. Archaeological investigations highlighted that the length of the wall is $1500 \mathrm{~m}$ and $1100 \mathrm{~m}$ in NS and WE directions, respectively. Only some portions of the walls survive with a $60 \sim 70 \mathrm{~m}$ width at present. The surveyed area is located on the eastern wall, with a residual height of about $6 \mathrm{~m}$. After a conventional GPR processing flow, the dual-frequency GPR profiles were combined with the proposed data fusion strategy. Figure 3 provides the fitness value of the optimal individual in each generation, which gradually converges as generations increase. We chose 2000 as the final optimized generation value.

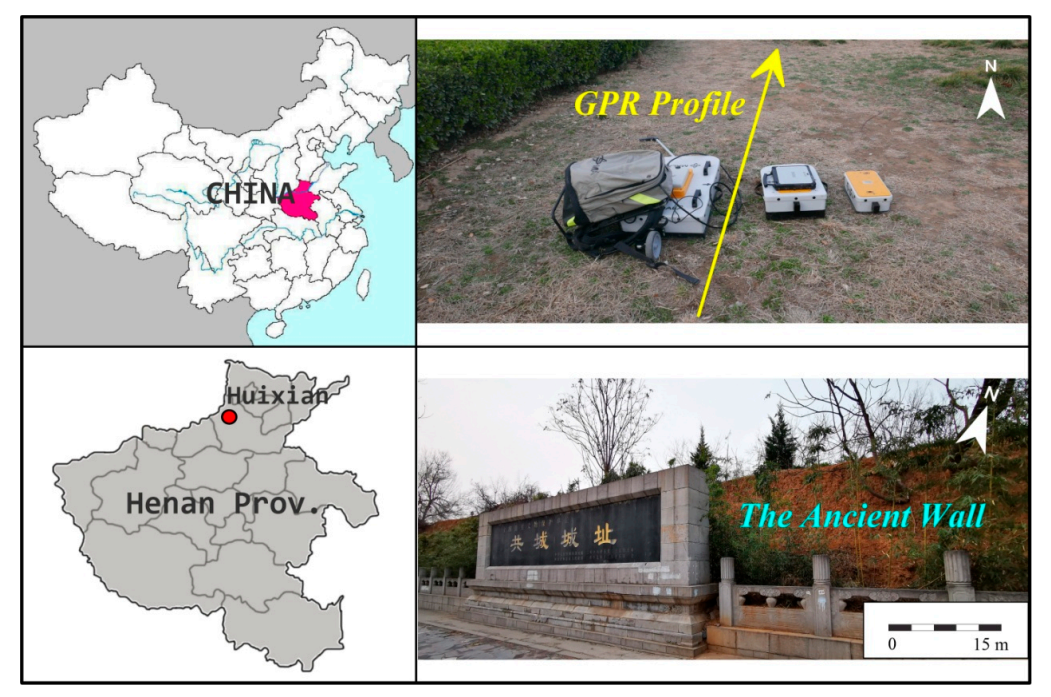

Figure 2. Location map and photos of the test site of case study I, at Huixian, Henan Province, China. 


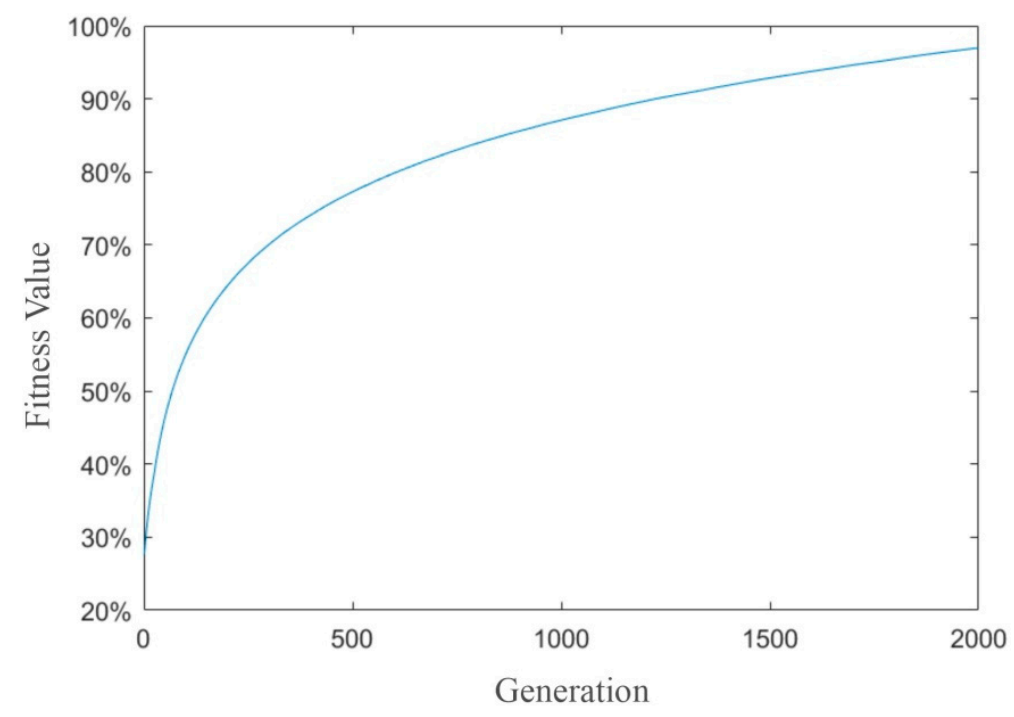

Figure 3. Fitness value variation for increasing generations.

Figure 4 shows the processed single-frequency profiles and the obtained fused profile. We can see that high-amplitude continuities related to rammed layers can be clearly identified, as the surface topography is almost flat and the subsurface conditions are not complicated or challenging. In addition, the GPR data acquired with a $250 \mathrm{MHz}$ frequency (Figure 4a) have an overall deeper penetration, while $800 \mathrm{MHz}$ data (Figure $4 \mathrm{~b}$ ) exhibit higher resolution but information is limited to the shallower layers. The fused profile (Figure 4c) has a more comprehensive characterization for inner layer distributions as well as details of shallower structures. Figure 5 shows the signal spectra of $800 \mathrm{MHz}$, $250 \mathrm{MHz}$, and the fused profile, which are derived from the whole dataset. Compared with single-frequency profiles, the fused profile demonstrates the bandwidth widening.

\subsection{Case Study II: Multi-Frequency GPR Data Fusion to Characterize Archaeological Features within a Natural Stratigraphic Sequence}

Case study II focuses on 2D multi-frequency (i.e., $300 \mathrm{MHz}$ and $500 \mathrm{MHz}$ ) GPR archaeological surveys close to the village of San Vincenzo, on Stromboli Island, Italy. The area is characterized by a rough topographic surface and geometrically irregular targets with limited lateral continuity. Evidence of a prehistoric village, dating back to the Early Middle Bronze Age (about 2300-1400 BC), was found in 1980, accompanied by archaeological remains associated with different periods, including Classical, Hellenistic, and Contemporary. We have published high-resolution GPR characterization results of archaeological features obtained just considering $500 \mathrm{MHz}$ antennas in the study area [1]. The penetration of radar waves and the overall signal-to-noise ratio are quite low due to the chaotic background characterized by the superposition of ashes and lava flows mixed with loose volcaniclastic debris. The data fusion offers a challenging opportunity to improve the imaging and characterization of the subsurface. The same optimized generation value was chosen as in the previous case study.

From the $500 \mathrm{MHz}$ processed profile (Figure 6a), we can identify high-amplitude GPR reflections/diffractions, some of them associated with potential archaeological features. Further targets of potential interest can be identified below $90 \mathrm{~ns}$ in the $300 \mathrm{MHz}$ section (Figure $6 \mathrm{~b}$ ). The fused profile (Figure $6 \mathrm{c}$ ) retains the shallow features as well as the deeper ones, i.e., below the white dotted line. A topographic correction was applied to the fused profile (Figure 7) using a mean EM velocity equal to $0.12 \mathrm{~m} / \mathrm{ns}$. Based on the preliminary analysis [1], continuous layers ' $\mathrm{M}$ ' and ' $\mathrm{N}$ ' were tracked, which were associated with volcanic ash layers. In addition, comparing GPR information with the first excavations, we correlated the reflections close to layer ' $\mathrm{M}$ ' to archaeological remains of the Classical period, while reflections below layer ' $\mathrm{N}$ ' are related to archaeological structures of the Bronze Age 
(Figure 8). In addition, a newly identified layer ' $\mathrm{F}$ ' can be tracked from the fused profile (Figure 7), associated with another geological unit, composed of pyroclastic products with local alluvial and colluvial sediments and lava blocks.
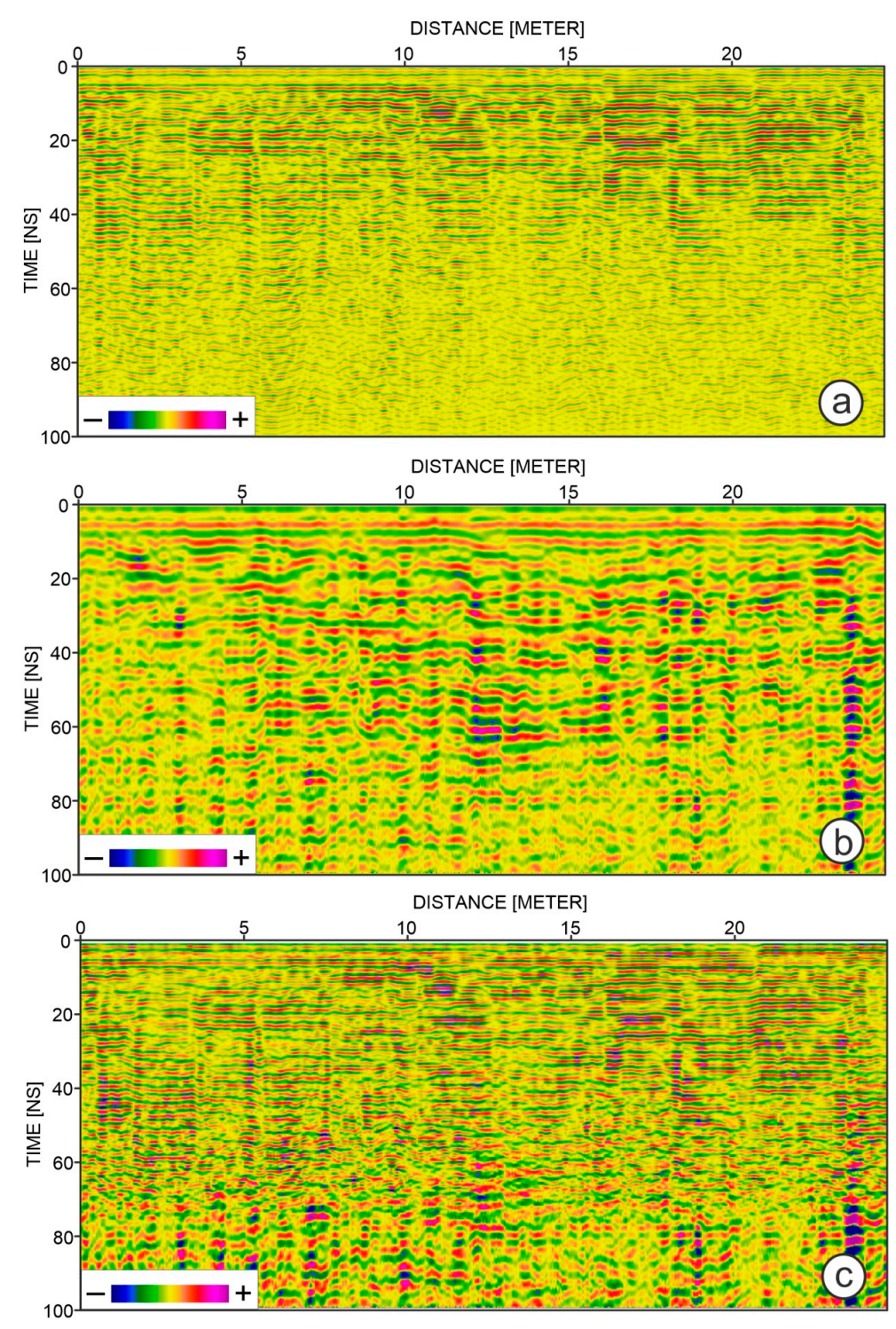

Figure 4. The processed single-frequency profiles, $800 \mathrm{MHz}(\mathbf{a}), 250 \mathrm{MHz}(\mathbf{b})$, and the fused profile (c) for case study I.

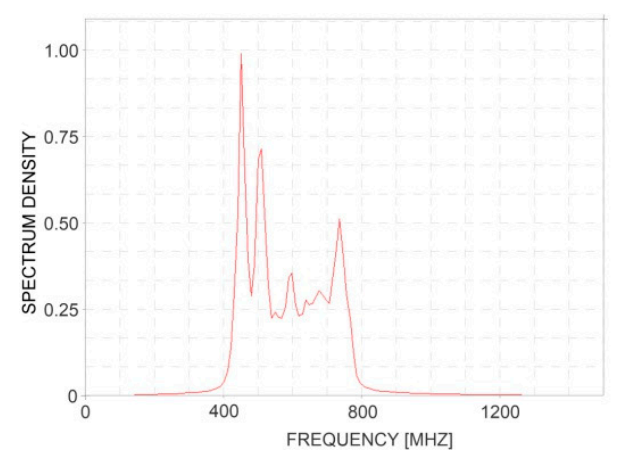

(a)

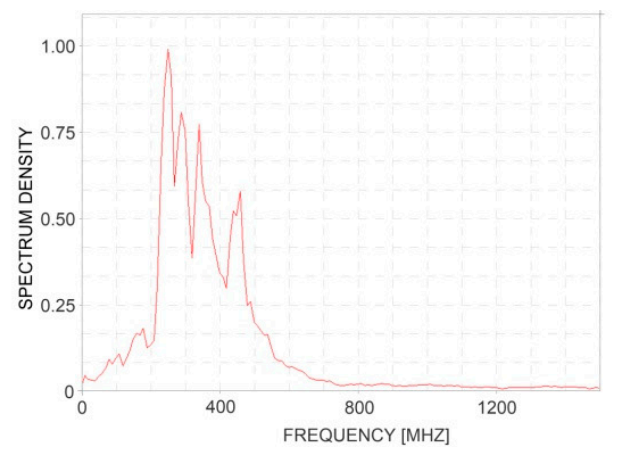

(b)

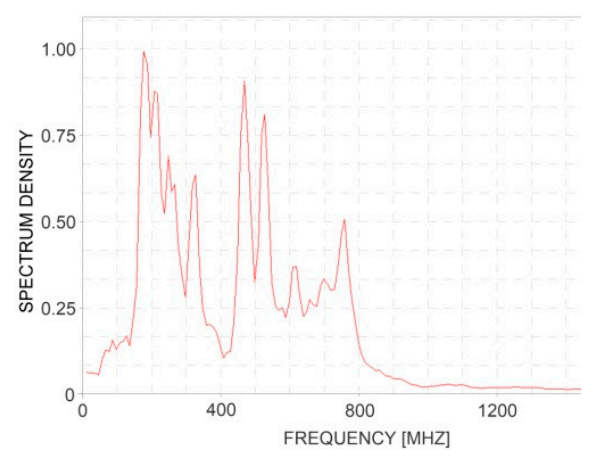

(c)

Figure 5. Signal spectra of $800 \mathrm{MHz}(\mathbf{a}), 250 \mathrm{MHz}$ (b), and the fused profile (c) for case study I. 

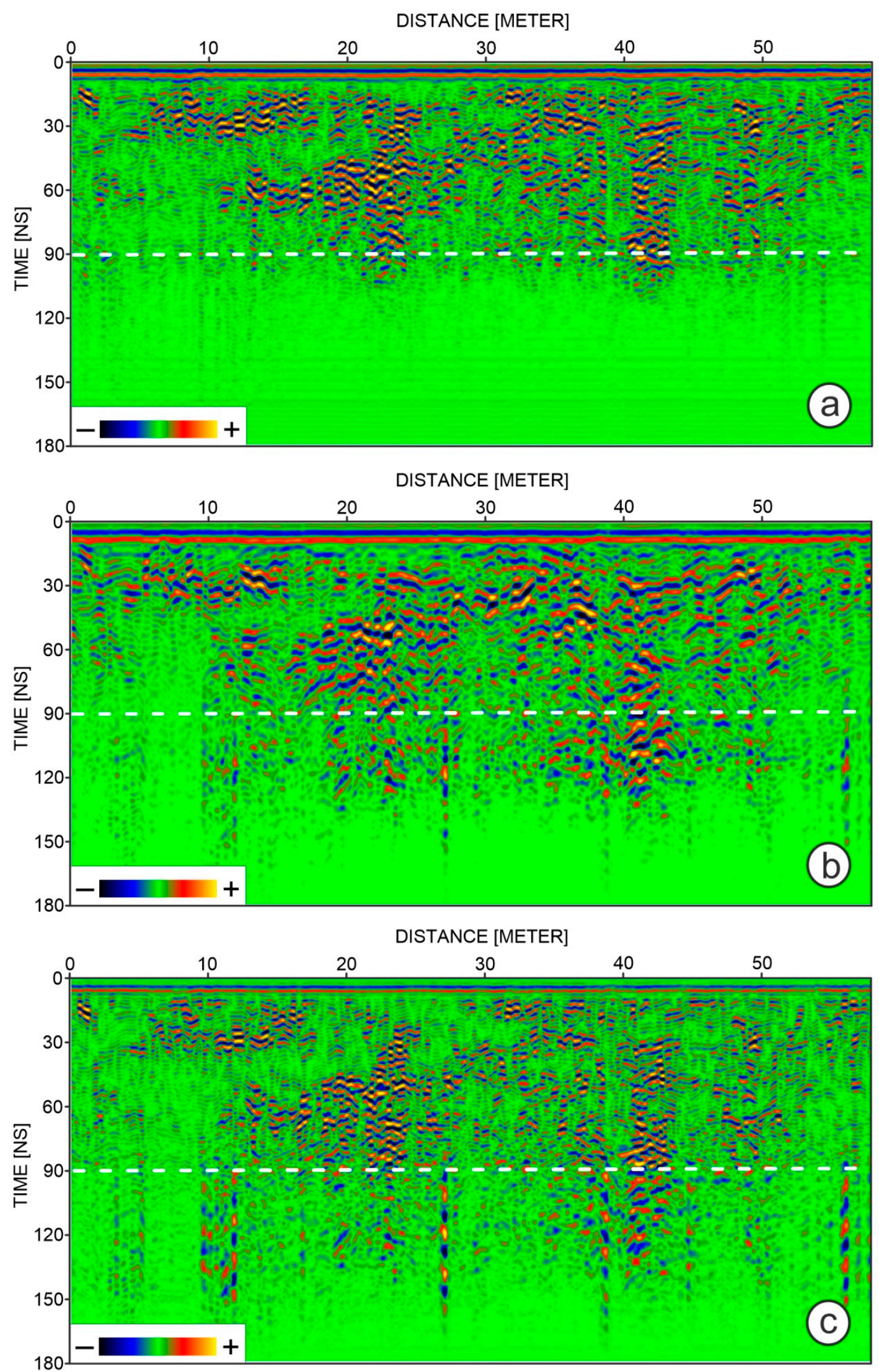

Figure 6. The processed single-frequency profiles, $500 \mathrm{MHz}(\mathbf{a}), 300 \mathrm{MHz}$ (b), and the fused profile (c) for case study II. Features deeper than the white dashed line are not visible on the high-frequency profile. 


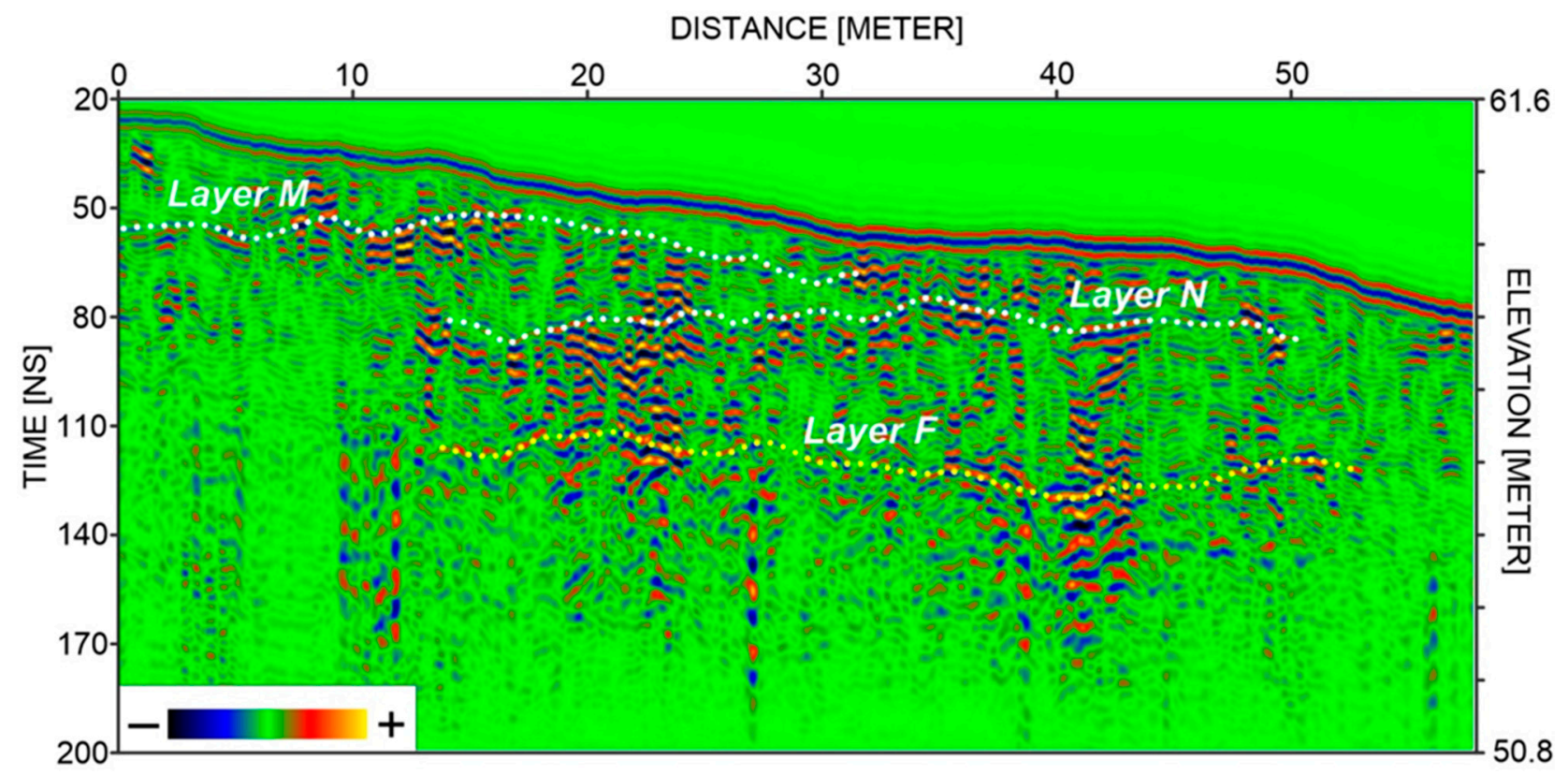

Figure 7. GPR interpretation based on the fused profile after topographic correction for case study II. Layers ' $\mathrm{M}$ ' and ' $\mathrm{N}$ ' were also tracked in the preliminary analysis (see reference [1]), while a new layer ' $\mathrm{F}$ ' can be recognized from the fused profile.
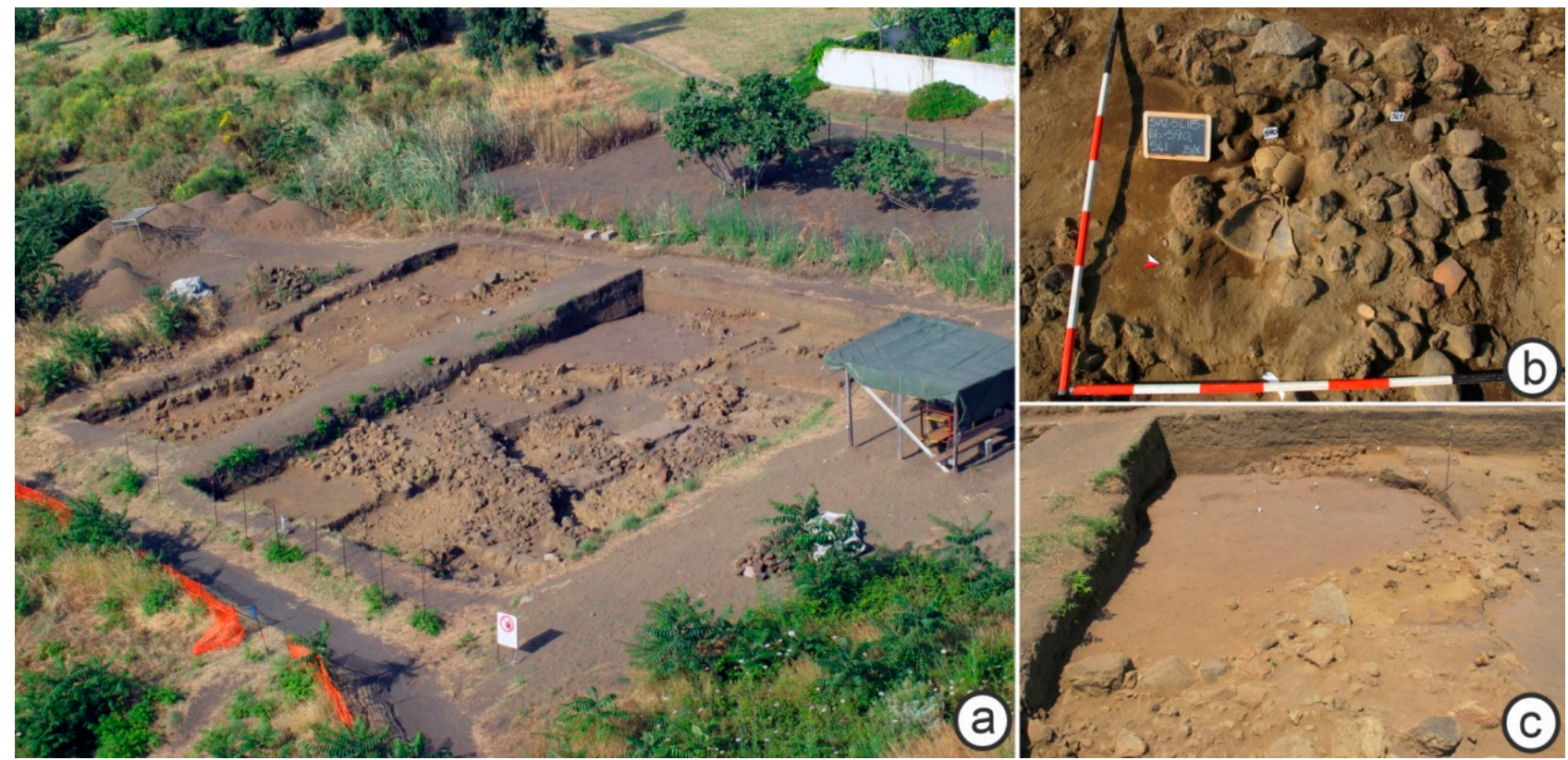

Figure 8. Photographs showing archaeological excavation site (a), excavated archaeological remains of the Classical period (b), and archaeological structures of the Bronze Age (c).

\section{Discussion and Conclusions}

We proposed a novel multi-frequency GPR data fusion method based on an adaptively weighted mode by a GA. Our main purpose is to keep dominant components from GPR profiles of different frequencies, not only to obtain high-resolution information in the shallow part but also to take advantage of the higher investigation depths for the low-frequency antenna. It is crucial to construct a suitable and effective objective function during the data fusion for the GA and we thus chose the least squares method to minimize the error between the fused signal and the fitted signal in the study, as it exhibits robust 
performances in a large range of conditions. Our proposed strategy, tested on two totally different archaeological case studies, provides encouraging results and opens the route towards further developments of multi-frequency GPR data interpretation for archaeological prospection, including the fusion of more than two frequency surveys.

On the other hand, multi-frequency GPR data fusion represents an important step in rapid GPR interpretation of large datasets, such as those acquired by the multi-channel systems that are increasingly used in archaeology. Furthermore, the output of data fusion is beneficial for further analysis of GPR data and automatic identification of potential subsurface targets. This is been driving an increasing interest in the GPR research community in developing more sophisticated data fusion methodologies and architectures, including integrated GPR attributes. Moreover, more fusion performance assessments, studying and evaluating the behavior of multi-frequency GPR data fusion, will consequently be refined and examined for further analysis to deal with challenging scenarios.

Author Contributions: Project administration, conceptualization, and writing: W.Z.; methodology and visualization: L.Y. and G.L.; GPR data analysis, review and editing: E.F., G.T., and M.P. All authors have read and agreed to the published version of the manuscript.

Funding: This research was supported by the National Natural Science Foundation of China (41904133), and the research funding of the School of Earth Sciences at Zhejiang University.

Acknowledgments: We acknowledge the Matlab campus grant for Zhejiang University. We further thank two anonymous reviewers for providing thoughtful and useful suggestions.

Conflicts of Interest: The authors declare no conflict of interest.

\section{References}

1. Zhao, W.; Forte, E.; Levi, S.T.; Pipan, M.; Tian, G. Improved high-resolution GPR imaging and characterization of prehistoric archaeological features by means of attribute analysis. J. Archaeol. Sci. 2015, 54, 77-85. [CrossRef]

2. Zhao, W.; Forte, E.; Pipan, M. Texture attribute analysis of GPR data for archaeological prospection. Pure Appl. Geophys. 2016, 173, 2737-2751. [CrossRef]

3. Zhao, W.; Forte, E.; Pipan, M.; Tian, G. Ground penetrating radar (GPR) attribute analysis for archaeological prospection. J. Appl. Geophys. 2013, 97, 107-117. [CrossRef]

4. Leucci, G.; De Giorgi, L.; Ditaranto, I.; Miccoli, I.; Scardozzi, G. Ground-Penetrating Radar Prospections in Lecce Cathedral: New Data about the Crypt and the Structures under the Church. Remote Sens. 2021, 13, 1692. [CrossRef]

5. Malagodi, S.; Orlando, L.; Piro, S.; Rosso, F. Location of archaeological structures using GPR method: Three-dimensional data acquisition and radar signal processing. Archaeol. Prospect. 1996, 3, 13-23. [CrossRef]

6. Masini, N.; Capozzoli, L.; Romano, G.; Sieczkowska, D.; Sileo, M.; Bastante, J.; Victoria, F.A.; Ziolkowski, M.; Lasaponara, R. Archaeogeophysical-based approach for inca archaeology: Overview and one operational application. Surv. Geophys. 2018, 39, 1239-1262. [CrossRef]

7. Soldovieri, F.; Orlando, L. Novel tomographic based approach and processing strategies for GPR measurements using multifrequency antennas. J. Cult. Herit. 2009, 10, e83-e92. [CrossRef]

8. Udphuay, S.; Paul, V.L.; Everett, M.E.; Warden, R.B. Ground-penetrating radar imaging of twelfth century Romanesque foundations beneath the thirteenth century Gothic abbey church of Valmagne, France. Archaeol. Prospect. 2010, 17, 199-212. [CrossRef]

9. Utsi, E.C.; Colls, K.S. The GPR investigation of the Shakespeare family graves. Archaeol. Prospect. 2017, 24, 335-352. [CrossRef]

10. Zhao, W.; Tian, G.; Forte, E.; Pipan, M.; Wang, Y.; Li, X.; Shi, Z.; Liu, H. Advances in GPR data acquisition and analysis for archaeology. Geophys. J. Int. 2015, 202, 62-71. [CrossRef]

11. Conyers, L.B.; Daniels, J.M.; Haws, J.A.; Benedetti, M.M. An Upper Palaeolithic landscape analysis of coastal Portugal using ground-penetrating radar. Archaeol. Prospect. 2013, 20, 45-51. [CrossRef]

12. Ruffell, A.; Geraghty, L.; Brown, C.; Barton, K. Ground-penetrating radar facies as an aid to sequence stratigraphic analysis: Application to the archaeology of Clonmacnoise Castle, Ireland. Archaeol. Prospect. 2004, 11, 247-262. [CrossRef]

13. Goodman, D.; Novo, A.; Morelli, G.; Piro, S.; Kutrubes, D.; Lorenzo, H. Advances in GPR imaging with multi-channel radar systems from engineering to archaeology. In Proceedings of the Symposium on the Application of Geophysics to Engineering and Environmental Problems, Charleston, SC, USA, 10-14 April 2011; pp. 405-411.

14. Gustavsen, L.; Stamnes, A.A.; Fretheim, S.E.; Gjerpe, L.E.; Nau, E. The Effectiveness of Large-Scale, High-Resolution GroundPenetrating Radar Surveys and Trial Trenching for Archaeological Site Evaluations-A Comparative Study from Two Sites in Norway. Remote Sens. 2020, 12, 1408. [CrossRef] 
15. Trinks, I.; Hinterleitner, A.; Neubauer, W.; Nau, E.; Löcker, K.; Wallner, M.; Gabler, M.; Filzweiser, R.; Wilding, J.; Schiel, H.; et al. Large-area high-resolution ground-penetrating radar measurements for archaeological prospection. Archaeol. Prospect. 2018, 25, 171-195. [CrossRef]

16. Trinks, I.; Johansson, B.; Gustafsson, J.; Emilsson, J.; Friborg, J.; Gustafsson, C.; Nissen, J.; Hinterleitner, A. Efficient, large-scale archaeological prospection using a true three-dimensional ground-penetrating radar array system. Archaeol. Prospect. 2010, 17, 175-186. [CrossRef]

17. Bi, W.; Zhao, Y.; Shen, R.; Li, B.; Hu, S.; Ge, S. Multi-frequency GPR data fusion and its application in NDT. NDTEE Int. 2020, 115, 102289 .

18. Booth, A.D.; Endres, A.L.; Murray, T. Spectral bandwidth enhancement of GPR profiling data using multiple-frequency compositing. J. Appl. Geophys. 2009, 67, 88-97. [CrossRef]

19. De Coster, A.; Lambot, S. Fusion of multifrequency GPR data freed from antenna effects. IEEE J. 2018, 11, 664-674. [CrossRef]

20. Kohl, C.; Krause, M.; Maierhofer, C.; Wöstmann, J. 2D- and 3D-visualisation of NDT-data using data fusion technique. Mater. Struct. 2005, 38, 817-826. [CrossRef]

21. Lu, G.; Zhao, W.; Forte, E.; Tian, G.; Li, Y.; Pipan, M. Multi-frequency and multi-attribute GPR data fusion based on 2-D wavelet transform. Measurement 2020, 166, 108243. [CrossRef]

22. Xiao, J.; Liu, L. Permafrost subgrade condition assessment using extrapolation by deterministic deconvolution on multifrequency GPR data acquired along the Qinghai-Tibet railway. IEEE J. 2015, 9, 83-90. [CrossRef]

23. Holland, J.H. Adaptation in Natural and Artificial Systems: An Introductory Analysis with Applications to Biology, Control, and Artificial Intelligence; MIT Press: Cambridge, MA, USA, 1992. 